Short Communication

\title{
ANALYSIS OF SURFACE AND VOLATILE COMPOUNDS OF FLOWER HEADS OF FLOURENSIA THURIFERA (MOL) D.C.
}

\author{
ALEJANDRO URZÚA*, ROCÍO SANTANDER, JAVIER ECHEVERRÍA
}

Universidad de Santiago de Chile, Facultad de Química y Biología, Departamento de Ciencias del Ambiente, Laboratorio de Química Ecológica, Casilla- 40, Correo- 33, Santiago, Chile.

(Received $26^{\text {th }}$ March 2007 - Accepted $11^{\text {th }}$ June 2007)

\begin{abstract}
Surface compounds were obtained by a methylene chloride extraction of fresh flower heads of Flourensia thurifera. The methylene chloride extract was purified by column chromatography and analyzed by GC-MS, leading to the identification of several monoterpenes, sesquiterpenes and diterpenes. A hydrocarbon fraction of n-alkanes from C23 to C31 and C33 was also identified. Headspace analysis of the fresh flower heads was also carried out. Different proportions of the same mono- and some of the sesquiterpenes were identified in the volatile fraction. The presence of mono- and sesquiterpenes in the flower heads is in agreement with the fact that these families of compounds have been identified in other Flourensia species.
\end{abstract}

keywords: Flourensia thurifera.; Asteraceae; Flower heads; Methylene chloride extract; Headspace; GC-MS; Monoterpenes; Sesquiterpenes; Diterpenes; Hydrocarbons

\section{INTRODUCTION}

Flourensia thurifera (Mol.) D.C. (Asteraceae, Heliantheae) is a shrub with attractive yellow flowers from 8 to $10 \mathrm{~cm}$ in diameter. The plant is found in semi-arid land in Central Chile from Los Vilos $\left(32^{\circ} \mathrm{S}\right.$ latitude) to beyond the latitude of Concepción $\left(37^{\circ} \mathrm{S}\right)$. It sometimes forms large and almost monospecific communities covering north facing slopes of hills ${ }^{1}$, although it can grow among other species. The flowers of $F$. thurifera have a pleasant smell, and recently the plant has started to be domesticated for use in gardens with low water requirements ${ }^{2}$.

In this communication, flower heads of Flourensia thurifera are studied by headspace analysis and methylene chloride extraction followed by GC-MS fractionating. The presence of mono- and sesquiterpenes in the flower heads is in agreement with the fact that these families of compounds have been identified in the leaf surface extract of Flourensia cernua ${ }^{3}$ and in the essential oil of Flourensia oolepsi ${ }^{4}$. Minor sesquiterpenoids and diterpenoids identified in the methylene chloride extract, were not detected in the headspace analysis, and the monoterpenoids were found in a greater proportion. These differences can be attributed to differences in the volatility of the compounds and plant control of the compartmentation

\section{EXPERIMENTAL}

\section{Plant Material}

Flourensia thurifera (Mol.) D.C. (Asteraceae, Heliantheae) flower heads, were collected in November 2005, between Zapallar and Papudo (V Region, Chile $32^{\circ} 30^{\prime} \mathrm{S}, 71^{\circ} 30^{\prime} \mathrm{W}$ ). Voucher specimens were deposited in the Herbarium of the National Natural History Museum, Santiago, Chile

\section{Plant extraction}

Fresh flower heads of $F$. thurifera $(1.0 \mathrm{~kg})$ were extracted by dipping the fresh plant material in $5.0 \mathrm{~L}$ of cold $\mathrm{CH}_{2} \mathrm{Cl}_{2}$ for $60 \mathrm{~s}$ 5,6. The extraction was repeated twice.

\section{Column separation of the extracts}

After removal of the solvent under vacuum, the residue $(7.0 \mathrm{~g}, 0.7 \%)$ was chromatographed on a silica gel column ( $70 \mathrm{~g})$ using a pentane -methylene chloride -methanol step gradient (pentane, $75 \mathrm{~mL}$; pentane- $\mathrm{CH}_{2} \mathrm{Cl}_{2}$ 99:1, 60 $\mathrm{mL}$; pentane- $\mathrm{CH}_{2} \mathrm{Cl}_{2} 97: 3,90 \mathrm{~mL}$; pentane- $\mathrm{CH}_{2} \mathrm{Cl}_{2} 1: 1,105 \mathrm{~mL}$ and $\mathrm{CH}_{2} \mathrm{Cl}_{2}-$ MeOH 9:1, $270 \mathrm{~mL}$. Fractions, each of about $15 \mathrm{ml}$, were monitored by TLC (silica gel $\mathrm{HF}_{254}$; pentane- $\mathrm{CH}_{2} \mathrm{Cl}_{2}, 98: 2$ and $\mathrm{CH}_{2} \mathrm{Cl}_{2}-\mathrm{MeOH}, 95: 5$ ) to afford 40 fractions regrouped after TLC into five new fractions; A: 1-5 (0.902 g), B: 6-9 (0. 801g), C: $10-15$ (0.998 g), D: 16-22 (1.319 g) and E: 23-40 (2.668 g). The regrouped fractions A, B and $\mathbf{C}$ were analysed in triplicate by GC-MS.

\section{Collection of the headspace}

For headspace analysis, flower heads (ca. $300 \mathrm{~g}$ fr.wt) were gathered and placed inside a glass jar equipped with an inlet and an outlet. At the inlet, a compressed air cylinder, containing synthetic air made from extra pure oxygen and nitrogen with no detectable organic impurities, was attached through a regulator which controlled the air flow. At the outlet, a column was attached which contained Porapak Q $(100 \mathrm{mg})$. Volatile entrainment $(5 \mathrm{~h}$ with air flow of $0.5 \mathrm{~L} / \mathrm{min}$ ) commenced immediately after the flowers had been severed from the plants. After collection of the headspace, the compounds in the Porapak Q column were removed with $\mathrm{CH}_{2} \mathrm{Cl}_{2}(0.5 \mathrm{ml})$. The solution was stored at $-18^{\circ} \mathrm{C}$, also under purified $\mathrm{N}_{2}$ until GC-MS analysis. The experiment was performed in triplicate.

\section{Analysis of the constituents}

The methylene chloride fractions (A, B and C), that contained the terpenoids (TLC), and the headspace fractions, were analysed in triplicate by GC-MS, using a FISONS MD-800 equipped with a J \& W DBS-MSD capillary column $(15 \mathrm{~m} \times 0.20 \mathrm{~mm}, 0.25 \mu \mathrm{m}$ film thickness). The temperature of the injector was $295{ }^{\circ} \mathrm{C}$ and the temperature of the column was programmed to start at $60^{\circ} \mathrm{C}$, for $2 \mathrm{~min}$, followed by a rise to $305^{\circ} \mathrm{C}$ at $10^{\circ} \mathrm{C} \mathrm{min}^{-1} \mathrm{Helium}$ was the carrier gas at $7 \mathrm{lb}$. psi. Detection was done using QI and EI. The identification of the components was performed by comparison of their retention times with those of pure authentic samples and by means of their retention indices (RI). Limonene, $\alpha$-pinene, $\beta$-pinene, linalool, 1, 8-cineol, $\alpha$-ocimene, $\alpha$-cubebene, $\alpha$-copaene, $\alpha$-humulene, alloaromadendrene, $\beta$-caryophyllene, phytol, isophytol and nalkanes were obtained from Aldrich-Sigma USA. The other compounds show their retention indexes and MS data in good agreement with both the literature ${ }^{7-10}$ and with data from the NIST library, with correlation indices larger than $97 \%$.

\section{RESULTS AND DISCUSSION}

The results of the GC-MS analysis are given in Table 1. Analysis of the methylene chloride extract of fresh flower heads resulted in the identification of 36 constituents which collectively accounted for more than $82 \%$ of the analysed fractions (constituents detected 45: identified: 36 ).

Minor sesquiterpenoids and diterpenoids identified in the methylene chloride extract, were not detected in the headspace analysis, and the monoterpenoids were found in a greater proportion. These differences can be attributed to differences in the volatility of the compounds and plant control of the compartmentation ${ }^{11}$.

The presence of mono- and sesquiterpenoids in the flower heads of Flourensia thurifera is in agreement with the chemistry of other Flourensia spp. The leaf surface extracts of Flourensia cernua shows the presence of mono- and sesquiterpenoids: camphene, $\beta$-myrcene, 3 -carene, limonene, 1,8-cineole, borneol, cis-jasmone, $\beta$-caryophyllene, caryophyllene oxide and globulol. These were consistently present in different samples along with several unidentified compounds, some of which were tentative identified as: $\beta$-cubebene, $\alpha$-copaene, $\gamma$-cadinene, $\alpha$-humulene and $\beta$-bourbonene ${ }^{3}$. From the essential oil of Flourensia oolepsi, a total of 36 terpenoids were identified and the main components were t-cadinol (10.5\%), $\beta$-selinene $(9.8 \%)$, linalool $(8.2 \%)$ and $\beta$-eudesmol $(8.0 \%)^{4}$.

Even though some of these molecules and structural types are repeated 
among species, a clear terpene pattern implying chemosystematic correlations in these species of Flourensia could not be found.

Finally, flower heads of Flourensia thurifera are visited by a varied entomofauna and, although no systematic studies have been performed, the knowledge of the volatile components responsible of eventual odorous stimuli is important for future studies of interactions between $F$. thurifera and insects ${ }^{12}$.

Table 1. Chemical composition of $\mathrm{CH}_{2} \mathrm{Cl}_{2}$ extract and headspace from flower heads of $F$. thurifera.

\begin{tabular}{|c|c|c|c|c|}
\hline \multirow[t]{2}{*}{ Components } & \multicolumn{2}{|c|}{$\mathrm{CH}_{2} \mathrm{Cl}_{2}$ Extract } & \multicolumn{2}{|c|}{ Headspace } \\
\hline & RI & $(\%)^{a}$ & RI & $(\%)^{a}$ \\
\hline \multicolumn{5}{|l|}{ Monoterpenes } \\
\hline $\begin{array}{l}\text { p-metha-1(7)-3- } \\
\text { diene }\end{array}$ & 923 & $0.6(0.100)$ & 923 & $2.6(0.030)$ \\
\hline$\alpha$-pinene & 939 & $0.4(0.001)$ & 934 & $3.9(0.040)$ \\
\hline$\beta$-pinene & 977 & $0.6(0.060)$ & 977 & $2.7(0.030)$ \\
\hline limonene & 1031 & $1.0(0.100)$ & 1031 & $3.7(0.040)$ \\
\hline 3-thujene & 1038 & $0.4(0.010)$ & 1035 & $3.3(0.020)$ \\
\hline$\alpha$-ocimene & 1044 & $10.1(0.600)$ & 1044 & $30.1(2.200)$ \\
\hline linalool & 1098 & $2.1(0.010)$ & 1098 & $3.1(0.30)$ \\
\hline 1,8 cineol & 1228 & $0.3(0.005)$ & 1228 & $3.8(0.20)$ \\
\hline \multicolumn{5}{|l|}{ Sesquiterpenes } \\
\hline$\alpha$-cubebene & 1350 & $19.1(1.200)$ & 1350 & $15.1(1.400)$ \\
\hline$\alpha$-copaene & 1375 & $0.6(0.130)$ & & \\
\hline$\beta$-cubebene & 1388 & $1.3(0.120)$ & 1388 & $1.1(0.040)$ \\
\hline$\beta$-caryophyllene & 1413 & $7.4(0.400)$ & & $5.7(1.200)$ \\
\hline 1(10)-aristolene & 1431 & $0.9(0.010)$ & & \\
\hline$\alpha$-humulene & 1453 & $1.4(0.020)$ & 1453 & $0.9(0.020)$ \\
\hline aristolene & 1458 & $1.3(0.010)$ & & \\
\hline ishwarane & 1460 & $1.3(0.010)$ & & \\
\hline alloaromadendrene & 1467 & $1.4(0.010)$ & & \\
\hline germacrene D & 1481 & $1.4(0.010)$ & & \\
\hline$\beta$-selinene & 1487 & $1.1(0.040)$ & & \\
\hline$\gamma$-cadinene & 1512 & $1.3(0.100)$ & & \\
\hline 3,7(11)-selinadiene & 1531 & $1.3(0.120)$ & & \\
\hline$\alpha$-cadinene & 1538 & $0.7(0.010)$ & & \\
\hline germacrene B & 1557 & $3.4(0.080)$ & 1557 & $3.6(0.20)$ \\
\hline spathulenol & 1577 & $1.4(0.100)$ & & \\
\hline \multicolumn{5}{|l|}{ Diterpenes } \\
\hline phytol & 1981 & $1.3(0.100)$ & & \\
\hline isophytol & 2210 & $1.7(0.120)$ & & \\
\hline \multicolumn{5}{|l|}{ Hydrocarbons } \\
\hline $\mathrm{C}_{23} \mathrm{H}_{48}$ & 2300 & $0.9(0.060)$ & & \\
\hline $\mathrm{C}_{24} \mathrm{H}_{50}$ & 2400 & $0.4(0.010)$ & & \\
\hline $\mathrm{C}_{25} \mathrm{H}_{52}$ & 2500 & $1.7(0.120)$ & & \\
\hline $\mathrm{C}_{26} \mathrm{H}_{54}$ & 2600 & $0.3(0.006)$ & & \\
\hline $\mathrm{C}_{27} \mathrm{H}_{56}$ & 2700 & $3.2(0.030)$ & & \\
\hline $\mathrm{C}_{28} \mathrm{H}_{58}$ & 2800 & $0.4(0.003)$ & & \\
\hline $\mathrm{C}_{29} \mathrm{H}_{60}$ & 2900 & $12.1(0.900)$ & & \\
\hline $\mathrm{C}_{30} \mathrm{H}_{62}$ & 3000 & $3.2(0.070)$ & & \\
\hline $\mathrm{C}_{31} \mathrm{H}_{64}$ & 3100 & $2.1(0.020)$ & & \\
\hline $\mathrm{C}_{33} \mathrm{H}_{68}$ & 3300 & $0.3(0.005)$ & & \\
\hline
\end{tabular}

RI, retention indices (DB-5 column), for hydrocarbons $(\mathrm{Cn} \times 100)$ according to Kovats; ${ }^{\text {a }}$ area of the identified compounds; mean of three analyses (SD in parentheses).

\section{ACKNOWLEDGEMENTS}

Financial support from FONDECYT 1060033 is gratefully acknowledged.

\section{REFERENCES}

1. Hoffmann J A. Flora Silvestre de Chile, Zona Central, $3^{\circ}$ Ed. Ediciones Claudio Gay: Santiago Chile, 1995; pp. 238-239.

2. Riedemann P, Aldunate G. Flora Nativa de Valor Ornamental, Chile Centro, Editorial Andrés Bello: Santiago Chile, 2001; pp. 344-345.

3. Estell R E, Havstad K M, Fredrickson E L, Gardea-Torresdey L A. Biochem. Syst. Ecol. 22, 73 (1994).

4. Priotti Z E, Zygadlo J A, Espinar L A, J. Essent. Oil Res. 9, 345 (1979).

5. Urzúa A. J. Chil. Chem. Soc. 49, 137 (2004).

6. Urzúa A, Santander R, Echeverría J, Rezende C M. J. Chil. Chem. Soc. 52, 1142-1144 (2007).

7. Masry S, Abou-Donia A, Darwisch A F, Abou-Karam A M, Grenz M, Bohlmann F. Phytochemistry 12, 2953 (1984).

8. Swingar A A, Silverstein R M. Monoterpenes Infrared, Mass, ${ }^{I} H$ NMR, and ${ }^{13}$ C NMR Spectra, and Kováts Indices, Aldrich Chemical Company, Inc.: Milwaukee USA, 1981.

9. Connolly J D, Hill R A. Dictionary of Terpenoids Volume 1, Mono- and Sesquiterpenoids, Chapman and Hall: London U K, 1991.

10. Vig O P. J. Indian Chem. Soc. 4, 159 (1972).

11. Shoonhoven M L, A van Loon J A J, Dicke M. Insect-Plant Biology (Chapter 4, Plant chemistry: endless variety), Oxford University Press: London U K, 2005; pp. 48-86.

12. Shoonhoven M L, A van Loon J A J, Dicke M. Insect-Plant Biology (Chapter 6,Host- Plant selection: how to find a host plant), Oxford University Press: London U K, 2005; 135-160. 